\title{
Anti-inflammatory effects of astroglial a7 nicotinic acetylcholine receptors are mediated by inhibition of the NF-KB pathway and activation of the Nrf2 pathway
}

\author{
Hiral Patel ${ }^{1,2^{*}}$ D, Jessica McIntire ${ }^{3}$, Sarah Ryan ${ }^{3}$, Anthone Dunah $^{2}$ and Ralph Loring ${ }^{1}$
}

\begin{abstract}
Background: a7 nicotinic acetylcholine receptors (nAChRs) are widely distributed throughout the central nervous system and are reported to have neuroprotective properties. a7 nAChRs are expressed on astrocytes, which are key regulators of neuroinflammation and oxidative stress in several neurodegenerative diseases. However, the anti-inflammatory and antioxidant properties of astroglial a7 nAChRs are not well studied. Therefore, we evaluated the role of astroglial a7 nAChR activation in neuroinflammation.

Methods: Anti-inflammatory and antioxidant effects of a7 nAChR activation were evaluated in an in vitro mouse model of neuroinflammation using lipopolysaccharide (LPS) in primary astrocyte cultures. a7 nAChR anti-inflammatory effects on the NF-KB pathway were evaluated using ELISA, gene expression analysis, immunofluorescence, and western blotting. Antioxidant effect of a7 nAChR activation on expression profiles of canonical Nrf2 target genes was examined by quantitative PCR and western blotting. The role of the Nrf2 pathway in a7 nAChR-mediated anti-inflammatory response was evaluated using Nrf2 knockout astrocytes. Brain ex vivo NF-kB luciferase signals were evaluated after treatment with an a7 nAChR agonist in lipopolysaccharide (LPS)-injected NF-kB luciferase reporter mouse model.

Results: Astrocytes treated with the a7 nAChR partial agonist (GTS21) showed significantly reduced LPS-mediated secretion of inflammatory cytokines and this effect was reversed by the a7 nAChR antagonist methyllycaconitine (MLA) and by knockdown of a7 nAChR expression with a short hairpin RNA. Further, a7 nAChR activation blocked LPS-mediated $\mathrm{NF}-\mathrm{kB}$ nuclear translocation indicating that the observed anti-inflammatory effect may be mediated through inhibition of the NF-KB pathway. Treatment with GTS21 also upregulated canonical Nrf2 antioxidant genes and proteins suggesting antioxidant properties of a7 nAChR in astrocytes. Using an astrocyte conditioned media approach, we demonstrated reduction in neuronal apoptosis when astrocytes were pretreated with GTS21. Finally, in an in vivo neuroinflammation model using LPS in NF-KB luciferase reporter mice, we demonstrated reduction in LPS-induced NF-kB activity and pro-inflammatory cytokines with GTS21 treatment in brain tissue.
\end{abstract}

Conclusion: Our results suggest that activating astroglial a7 nAChRs may have a role in neuroprotection by decreasing inflammation and oxidative stress, and therefore could have therapeutic implication for disease modifying treatments of neurodegenerative diseases.

Keywords: a7 nicotinic acetylcholine receptors, Astrocytes, NF-KB pathway, Nrf2 pathway

\footnotetext{
* Correspondence: patel.hira255@gmail.com

${ }^{1}$ Department of Pharmaceutical Sciences, Northeastern University, Boston, MA, USA

${ }^{2}$ Neurology Research, Biogen, 225 Binney street, Cambridge, MA 02142, USA

Full list of author information is available at the end of the article
} 


\section{Background}

$\alpha 7$ nicotinic acetylcholine receptors (nAChRs) are widely distributed throughout the central nervous system (CNS) and periphery [1]. Within the CNS, these receptors are expressed in neurons and glial cells and are actively involved in learning, memory, and attention [2]. Observations from neuronal cell lines, primary neuron cultures, and transgenic mice with deleted $\alpha 7 \mathrm{nAChR}$ indicate that agonists of these receptors, including galantamine (an allosteric modulator), PNU-282987, TC-1698, and GTS21 (3-[2,4-dimethoxybenzylidene]anabaseine), provide neuroprotection against toxicity induced by various insults such as amyloid-beta, glutamate, okadaic acid, and ethanol which are reversed by $\alpha 7 \mathrm{nAChR}$ antagonists such as methyllycaconitine (MLA) or $\alpha$-bungarotoxin [3-10]. Therefore, $\alpha 7 \mathrm{nAChRs}$ are of great interest as potential therapeutic target in various neurodegenerative diseases.

While the neuroprotective role of $\alpha 7 \mathrm{nAChRs}$ is well characterized, limited evidence exists regarding the potential anti-inflammatory properties of these receptors in astrocytes. Functional $\alpha 7 \mathrm{nAChRs}$ are reported to be present on astrocytes, which upon activation increase intracellular calcium levels [11]. Some preliminary data point towards potential anti-inflammatory effects mediated through $\alpha 7 \mathrm{nAChRs}$ expressed in astrocytes. Liu et al. demonstrated that activation of astroglial $\alpha 7$ nAChRs may provide protection against degeneration of dopaminergic neurons by inhibition of MPTP (in vivo)- and MPP+- or LPS (in vitro)-induced astrogliosis in Parkinson's disease [12]. However, the molecular mechanism of the observed anti-inflammatory response of $\alpha 7$ nAChR and resultant neuroprotection has not been studied. In non-neuronal cells such as monocytes and macrophages, anti-inflammatory properties of $\alpha 7 \mathrm{nAChRs}$ are reported to be mediated through inhibition of the NF- $\mathrm{KB}$ pathway $[13,14]$. More recently, it has been demonstrated that activation of $\alpha 7 \mathrm{nAChRs}$ in glial cells leads to blocking of the NF- $\mathrm{kB}$ pathway and a consequent reduction in neuroinflammation [15]. Another emerging mechanism that may explain $\alpha 7 \mathrm{nAChR}$-mediated neuroprotection is the Nrf2 pathway. Nrf2 is a member of the NF-E2 family of basic region leucine-zipper transcription factors and responds to oxidative and electrophilic stress by regulating antioxidant responsive genes. Recent evidence from rat organotypic hippocampal slice culture suggests that $\alpha 7 \mathrm{nAChR}$ agonists induce heme oxygenase 1 via the Nrf2 pathway in a brain ischemic model, which provides neuroprotection [16].

Evaluating the potential role of astroglial $\alpha 7 \mathrm{nAChRs}$ is critical because astrocytes are the most abundant cell type in the brain, representing $20-40 \%$ of the brain cells. Astrocytes are increasingly being recognized as important mediators of neuroinflammation and consequent cognitive impairment [17, 18]. Therefore, targeting astroglial $\alpha 7 \mathrm{nAChRs}$ for their neuroprotective properties may be important in guiding development of disease modifying treatments for various neurodegenerative diseases. Thus, we used in vitro and in vivo models of neuroinflammation to elucidate the molecular mechanism for anti-inflammatory and antioxidant properties of $\alpha 7$ nAChRs activation in astrocytes, based on the hypothesis that the crosstalk between the NF- $\mathrm{kB}$ and Nrf2 pathways mediates these effects.

\section{Methods \\ Cell culture}

Astrocytes were purified from cortices of postnatal day 2 C57BL/6 mouse pups using a shaking method described by McCarthy and de Villis [19]. Briefly, we first dissected the cortical tissues and then removed the meninges. The tissues were then centrifuged and washed with cold Hank's Balanced Salt Solution (HBSS). Tissue dissociation was performed using Papain-based Neural Tissue Dissociation Kit (Miltenyi Biotec, Inc.).Tissues were further incubated with DNAse and mixed until well dissociated. After dissociation, cells were filtered, centrifuged, and resuspended in DMEM supplemented with 20\% fetal bovine serum (FBS), penicillin, and streptomycin. Finally, cells were counted and plated in poly-D-lysine coated T-75 $\mathrm{cm}^{2}$ flasks. Medium was replaced after 4-5 $\mathrm{h}$ and then every 3 days. After 8 days in culture, flasks were shaken on an orbital shaker for 18-20 h at $200 \mathrm{rpm}$ to release microglia and oligodendrocytes from the mixed cultures. Purified astrocytes were then trypsinized and replated for assay.

Neurons were isolated from embryonic day 16-18 mouse brains. Brains were first collected in a $100-\mathrm{cm}$ petri dish filled with cold HBSS. Next, the brainstem and meninges were removed using a dissecting microscope. Then, cortices were dissected and collected in $15 \mathrm{ml}$ conical tube with HBSS. Cortical tissues were washed with cold sterile HBSS twice followed by addition of trypsin. Tissues were incubated with trypsin at $37{ }^{\circ} \mathrm{C}$ for $20 \mathrm{~min}$. After incubation, DNAse I was added to tissue for $30 \mathrm{~s}$. To meet the special cell culture requirements of pre-natal and embryonic neuronal cells, dissociated cells were filtered and plated in neurobasal medium (Gibco, catalog no. 21103, with 2\% B27 (Gibco, catalog no. 17504-044), 1\% glutamax (Gibco, catalog no. 35050), and 10 units $/ \mathrm{ml}$ penicillin streptomycin (Gibco, catalog no. 15140-148).

\section{Astrocyte treatment paradigm}

Astrocytes were plated in 24 well plates at the density of 100,000 cells/well in DMEM with 20\% FBS medium for $24 \mathrm{~h}$. Cells were serum starved before adding compounds. Cells were then stimulated with or without $60 \mathrm{ng} / \mathrm{ml}$ LPS (Sigma, L6529) in the presence or absence 
of different doses of GTS21 (Sigma) to measure cytokine levels.

\section{a7 nAchR gene knockdown with short hairpin RNA}

Astrocytes were transduced with either lenti short hairpin (sh)-RNA for $\alpha 7$ nAchR or scrambled shRNA in 6-well plate for 7 days. Two different sequences of 29 mer $\alpha 7$ nAchR-specific shRNA were used (GCCAACGACTCG CAGCCGCTCACCGTGTA, CTTGGAATAACTGTCTT ACTTTCTCTGAC) to maximize knockdown efficiency. Knockdown efficiency was determined using qRT-PCR with TaqMan probes specific for $\alpha 7 \mathrm{nAch}$ (Assay ID; Mm01312230_m1). Next, the cells were treated with LPS $(60 \mathrm{ng} / \mathrm{ml})$ in the presence or absence of $30 \mu \mathrm{m}$ GTS-21. After treatment, RNA was isolated from each condition and TNF levels were measured.

\section{Measurement of secreted TNF- $\alpha$ and IL- 6 using enzyme-linked immunosorbent assay (ELISA)}

TNF- $\alpha$ secretion was measured in purified astrocyte cultures treated with LPS in the presence or absence of GTS21. GTS21 pretreatment was done for $1 \mathrm{~h}$ followed by $24 \mathrm{~h}$ of LPS treatment. Following the treatment, cellfree culture medium was collected and TNF- $\alpha$ and IL- 6 were measured using a commercially available mouse colorimetric ELISA assay (eBiosciences) following the manufacturer's protocol.

\section{Immunocytochemistry}

For immunofluorescence, purified astrocytes were plated for $24 \mathrm{~h}$ and fixed with $4 \%$ paraformaldehyde for $15 \mathrm{~min}$ and washed three times with PBS. After fixation, cells were permeablized with $1 \times$ GDB buffer (Gelatin Solution, $0.3 \%$ Triton X-100, Phosphate Buffer, NaCl). Cells were then incubated with anti-GFAP antibody (Sigma, G6171) and anti- NF-kB antibody (Abcam, ab16502) overnight at $4{ }^{\circ} \mathrm{C}$, followed by washing three times with PBS and $1 \mathrm{~h}$ incubation of Alexa- 488 or 594 conjugated secondary antibody (Thermofisher). DAPI (Thermofisher) was used as nuclear stain.

For $\alpha$-bungarotoxin labeling, primary astrocytes were plated in 96-well plate at 20,000 cells per well for $24 \mathrm{~h}$. Thereafter, cells were pretreated with $200 \mu \mathrm{m}$ nicotine for $15 \mathrm{~min}$ followed by treatment with Alexa Fluor 488-conjugated $\alpha$-bungarotoxin (B13422, Thermofisher Scientific) at $4{ }^{\circ} \mathrm{C}$ for $15 \mathrm{~min}$. Immediately following incubation, these cells were washed with PBS three times and then fixed for $15 \mathrm{~min}$ in $4 \%$ paraformaldehyde at room temperature. After fixation, cells were washed twice with PBS and examined under a fluorescent microscope.

\section{Immunostaining quantitation}

Images were captured and analyzed using Cellomics ArrayScan XTI high-content analysis system. This system contains high-resolution photometrics X1 CCD, 14 bit camera used for automated image acquisition. The Cellomics Target Activation bioapplication was used for processing and analyzing the images to quantitate the percentage purity of astrocytes within a well, and the spot detection bioapplication was used to quantitate the percentage of NF- $\mathrm{kB}$ nuclear translocation and caspase $3 / 7$ fluorescence within a well.

\section{Total RNA extraction from cells}

Total RNA was extracted from astrocytes using RNeasy miniprep plus kit from Qiagen according to the manufacturer's instructions. Genomic DNA was eliminated using the genomic DNA eliminator column provided with the RNA isolation kit. Purified RNA was quantified using a NanoDrop ${ }^{\circ}$ ND-1000 UV-Vis Spectrophotometer. The quality of RNA was determined by using OD 260/OD 280 and OD 260/OD 230 which were approximately 1.8-2. Total RNA was reverse transcribed into DNA using a high capacity cDNA reverse transcription kit (Applied Biosystems) using the manufacturer's protocol.

\section{Total RNA extraction from tissues}

RNA extraction from frozen tissues was performed using QIAzol extraction method. Frozen tissues were collected in an RNase free deep-well plate (96-well plate from Corning, 3961). A $2.3 \mathrm{~mm}$ stainless steel bead was added to each of the frozen tissues. Tissues were then disrupted by adding QIAzol reagent followed by subjecting the block to Mini-Beadbeater for 4 cycles of $45 \mathrm{~s}$ each. This resulted in efficient disruption of the tissues. The aqueous layer was collected after mixing with chloroform. An equal volume of $70 \%$ ethanol was added to the aqueous layer, mixed thoroughly, and applied to RNeasy 96 plates (Qiagen). Purification of RNA was done according to the manufacturer's protocol.

\section{Real-time polymerase chain reaction (rt-PCR)}

Target gene primers along with 6-FAM ${ }^{\mathrm{m}}$ dye-labeled TaqMan micro groove binder probe for quantitative PCR analysis were obtained from Applied Biosystems (assay IDs Mm00516005_m1 for heme oxygenase 1 (HO1), Mm00443675_m1 for thioredoxin reductase (TXNRD1), Mm00802655_m1 glutamate-cystein ligase catalytic subunit (GCLC), and Mm00660947_m1 for oxidative stress-induced growth inhibitor (OSGIN1)). Each reaction contained $100 \mathrm{ng}$ of DNA, $900 \mathrm{nM}$ each of forward and reverse primers, and $250 \mathrm{nM}$ TaqMan probe. Temperature conditions consisted of a $10 \mathrm{~min}$ cycle at $95{ }^{\circ} \mathrm{C}$, followed by 40 cycles of $95^{\circ} \mathrm{C}$ for $0.15 \mathrm{~min}$ and $60{ }^{\circ} \mathrm{C}$ for $1 \mathrm{~min}$ using Stratagene Mx 3005P. All samples were measured in at least duplicates along with GAPDH as a normalizing gene, and the no-template control was 
negative for all runs. The final analysis was done using comparative CT method.

\section{Gene expression analysis}

The TaqMan ${ }^{\oplus}$ OpenArray ${ }^{\oplus}$ Gene Expression platform was used to perform a transcriptomic analysis to comprehensively evaluate inflammatory responses upon $\alpha 7$ $n A c h R$ activation in an in vitro inflammation model using LPS. Total RNA extracted from astrocytes treated with LPS alone and LPS in the presence of GTS21 was reverse transcribed into cDNA. The cDNA was then loaded to a TaqMan ${ }^{\odot}$ OpenArray ${ }^{\bullet}$ Mouse Inflammation Panel plate (Thermofisher, 4475393) consisting of 632 gene targets selected for their involvement in inflammatory responses. The QuantStudio 12K Flex Real-Time PCR System (Thermofisher) was used to perform realtime PCR and quantitative gene expression. Fold changes (RQ) in expression of inflammatory genes were calculated using comparative CT method. A corrected $p$ value of 0.05 was used to identify differentially expressed genes.

Next, based on these differentially expressed genes, a gene set enrichment analysis was conducted using the software package Generally Applicable Gene-set Enrichment (GAGE) in R Bioconductor [20]. This software provides a list of Kyoto Encyclopedia of Genes and Genomes (KEGG) mouse pathways that are enriched by the differentially expressed genes. We aimed to identify pathways that are significantly downregulated upon treatment with GTS21. The $\mathrm{R}$ package, Pathview, was used to visualize maximally enriched KEGG pathways.

\section{Nitrite assay}

We used the Griess reagent (Promega) to evaluate the production of nitrite $\left(\mathrm{NO}_{2}^{-}\right)$, which is a breakdown product of nitric oxide (NO). Astrocytes were pretreated with GTS21 followed by LPS treatment for 3 days in DMEM in the absence of phenol red. After the treatment, cell-free conditioned medium was collected for the assay. First, the medium was incubated with reagent A containing sulfanilamide followed by incubation with reagent $B$, N-1-napthylethylenediamine dihydrochloride. This resulted in the formation of colored compound, which was measured at $540 \mathrm{~nm}$ using a microplate reader.

\section{Neuronal survival assay}

For this assay, we added LPS-treated astrocyte conditioned medium in the presence or absence of $\alpha 7 \mathrm{nAchR}$ agonist GTS21, in cultured neurons for $24 \mathrm{~h}$. Caspase-3 activation was measured using The CellEvent ${ }^{\circledR}$ Caspase-3/7 green detection reagent (Thermofisher). Images were captured and analyzed using Cellomics ArrayScan XTI high-content analysis system, and spot detection bioapplication was used for processing and analyzing the images to quantitate the percentage of caspase- 3 activation within a well.

\section{Protein isolation and western blot analysis}

Cells were scraped in $1 \times$ lysis buffer from Cell Signaling Technology (catalog no. 9803) with protease and phosphatase inhibitors and $0.5 \%$ SDS, followed by sonication with F60 Sonic Dismembrator (Fisher Scientific). The amount of protein in each sample was quantified using Pierce BCA Protein Assay Kit. All samples were diluted to the same concentration. For western blot analysis, samples were boiled at $95{ }^{\circ} \mathrm{C}$ for $5 \mathrm{~min}$ and $20 \mu \mathrm{g}$ of total protein was loaded on Criterion ${ }^{\mathrm{TM}} \mathrm{TGX}^{\mathrm{TM}}$ precast gels (BioRad Laboratories). Gels were run for $1 \mathrm{~h}$ at $150 \mathrm{~V}$ followed by transferring proteins onto a nitrocellulose membrane using an iBlot system (Invitrogen). Five percent non-fat dried milk in tris-buffered saline, tween 20 was used to block the membranes for $1 \mathrm{~h}$. After blocking, primary antibodies against GCLC (Abcam), NQO1 (Abcam), HO1 (Abcam), TXNRD1 (Abcam), ACTB (MP Biomedical), Phospho-IkB $\alpha$ (Abcam), and GAPDH (Abcam) were incubated overnight at $4{ }^{\circ} \mathrm{C}$, followed by washing with $1 \times$ tris-buffered saline, tween 20 for $30 \mathrm{~min}$. Secondary antibodies were then incubated at room temperature for $45 \mathrm{~min}$. After washing the membranes for $30 \mathrm{~min}$, Super Signal West Femto Substrate was added to detect horseradish peroxidase on the membranes. Chemiluminescence was measured and quantified using the Syngene gel imaging system.

\section{Animals}

All procedures involving animals were approved by the Biogen Institutional Animal Care and Use Committee, which is accredited by the Association for Assessment and Accreditation of Laboratory Animal Care International. Eight- to 12-week-old NF-kB luciferase reporter mice were used for in vivo experiments [21]. Four groups of five mice were used. In the first group, mice were administered with phosphate buffer saline (PBS) intraperitoneally twice; in the second group, mice were first administered with PBS followed by LPS $(1.7 \mathrm{mg} / \mathrm{kg})$ intraperitoneally; in the third group, mice were first administered with GTS21 ( $5 \mathrm{mg} / \mathrm{kg}$ ) followed by LPS $(1.7 \mathrm{mg} / \mathrm{kg})$ intraperitoneally; and in the fourth group, mice were first administered with GTS21 (25 $\mathrm{mg} / \mathrm{kg})$ followed by LPS (1.7 $\mathrm{mg} / \mathrm{kg})$ intraperitoneally. At $4 \mathrm{~h}$, mice were euthanized using $\mathrm{CO}_{2}$ asphyxiation method for ex vivo brain imaging and tissue collection.

\section{NF-кB luciferase brain ex vivo imaging}

Brain ex vivo NF-kB luciferase signals were evaluated in images acquired on the IVIS Spectrum instrument (Perkin Elmer, Hopkinton, MA), using the Perkin Elmer proprietary software, Living Image (v4.3.1). Luciferin was injected intraperitoneally at $150 \mathrm{mg} / \mathrm{kg}$ for ex vivo brain imaging, which was conducted after euthanizing the animal and harvesting the brain. One hemisphere of the 
brain was imaged, and the other half was collected for RNA analysis.

\section{Data analysis}

Experimental results were analyzed using GraphPad Prism software. Data are expressed as mean $(+/-$ standard deviation). Differences in means for continuous dependent variables were compared using unpaired Student $t$ tests (for two groups) or one-way ANOVA with adjustment for multiple comparisons (for more than two groups). Tukey's test was used for multiple comparisons when considering all pairwise comparisons and Dunnett's test was used when comparing multiple groups to a common control. Two-tailed $p$ values of less than 0.05 were considered as statistically significant.

\section{Results}

LPS triggers release of pro-inflammatory cytokines, NF-KB nuclear translocation, and morphological changes in astrocytes

The purity of astrocyte culture was measured by immunofluorescence by astrocyte cell specific marker, glial fibrillary acidic protein (GFAP). Using the ArrayScan XTI high-content analysis system, the purity was determined to be greater than $90 \%$ based on GFAP positive cells as a proportion of the total cell number (Fig. 1a). LPS is known to stimulate inflammatory responses in a variety of cells including astrocytes [12, 22]. Therefore, we used LPS as a stimulus to activate astrocytes and characterize their inflammatory response. We characterized the standard astrogliosis response upon LPS a

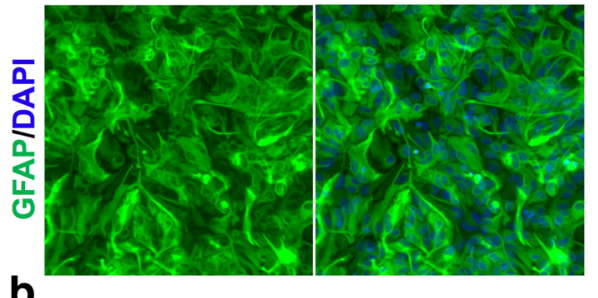

b

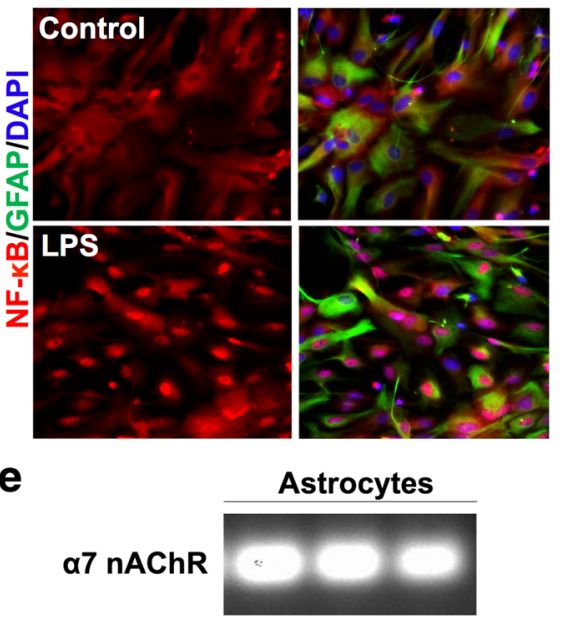

C
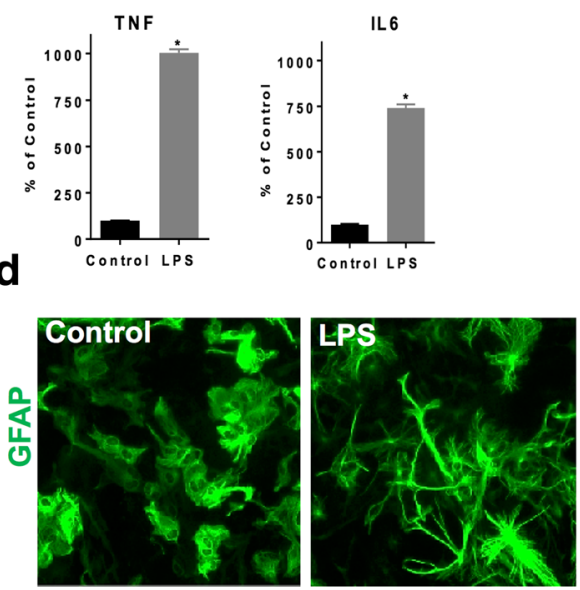

f

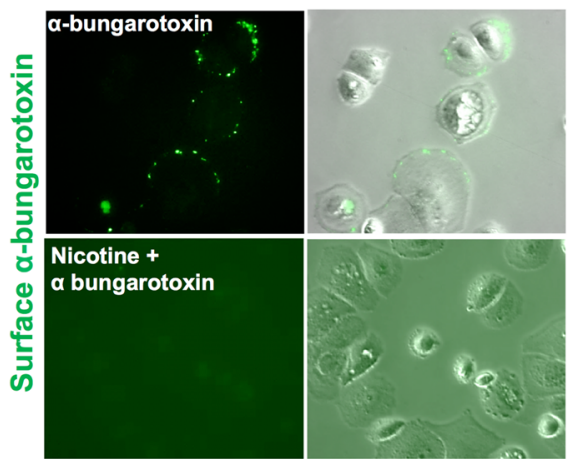

Fig. 1 Characterization of an in vitro model of neuroinflammation and expression of a7 nAchRs in mouse astrocytes. a These are representative images of mouse astrocytes using the Cellomics ArrayScan XTI high-content analysis system for automated image acquisition of 20 fields for each well at $\times 20$ magnification. In each field, two channels were captured to image nuclei (DAPI) and astrocyte marker (GFAP). The ArrayScan Target Activation bioapplication was used for processing and analyzing the images to quantify GFAP positive cells as percentage of total cell counts using DAPI within a well. This was found to be more than 90\%. b LPS (60 ng/ml) treatment for $3 \mathrm{~h}$ increased nuclear translocation of p65 subunit of NF-kB in astrocytes as a marker of acute inflammation phase. c LPS (60 ng/ml) treatment for $24 \mathrm{~h}$ resulted in significant increase in pro-inflammatory cytokines, TNF and IL-6, downstream of NF-KB activation in astrocytes, ${ }^{*} p<0.05$ as compared with untreated ( $t$ test). Error bars represent SD ( $\left.n=4\right)$. $\mathbf{d}$ Stimulation of astrocytes with LPS (60 ng/ml) for $24 \mathrm{~h}$ increased cell processes substantially as compared to the control cells. e a7 nAChR subunit mRNA expression observed in cultured astrocytes (three replicates). f Binding of fluorescently labeled a-bungarotoxin was observed in astrocytes. Pretreatment with $200 \mu \mathrm{m}$ nicotine (a7 nAchR agonist), significantly inhibited binding of fluorescently labeled a-bungarotoxin shown by decrease in fluorescence confirming expression of a7 nAchR in these cells 
treatment. As indicated in Fig. 1b, immunofluorescence showed a significant increase in NF- $\mathrm{kB}$ nuclear translocation after $3 \mathrm{~h}$ of LPS treatment as compared to untreated cells. As shown in Fig. 1c, we observed a statistically significant increase in pro-inflammatory cytokines TNF- $\alpha$ and IL- 6 measured using ELISA after $24 \mathrm{~h}$ of treatment with LPS. LPS also modified the morphology of astrocytes by increasing cell processes as compared to the control cells (Fig. 1d).

\section{a7 nAchRs are expressed in mouse astrocytes}

To evaluate the expression of $\alpha 7 \mathrm{nAChRs}$ in primary astrocyte cultures, we performed quantitative RT-PCR using TaqMan probes specific for $\alpha 7 \mathrm{nAChR}$ (Applied Biosystem
(ThermoFisher Scientific) assay ID Mm01312230_m1). As shown in Fig. 1e, our results confirm $\alpha 7$ nAChR subunit mRNA expression in cultured astrocytes. There was no genomic DNA detected in these samples (data not shown). Next, we evaluated surface binding of an impermeable competitive $\alpha 7 \mathrm{nAChR}$ antagonist, $\alpha$-bungarotoxin, to further confirm their expression on astrocytes. Upon treatment of astrocytes with Alexa fluor-488-labeled $\alpha$-bungarotoxin, we observed surface binding as shown in Fig. 1f. Pretreatment with nicotine significantly inhibited binding of fluorescently labeled $\alpha$-bungarotoxin shown by a decrease in fluorescence. Reduction in surface biding of $\alpha$-bungarotoxin, which is a competitive $\alpha 7$ $\mathrm{nAChR}$ antagonist, in the presence of an agonist (nicotine)

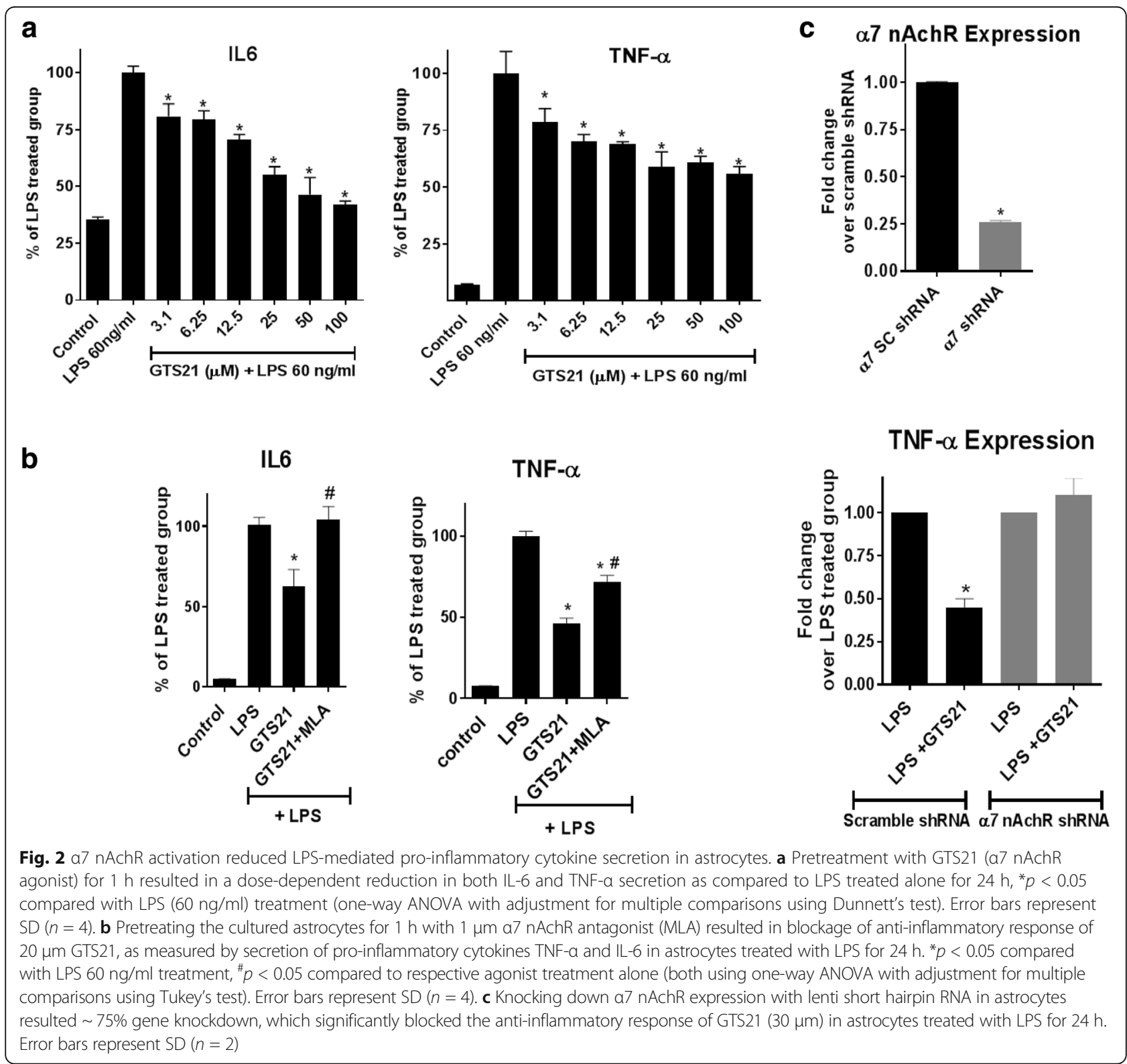


in our astrocyte cultures further confirms expression of $\alpha 7$ nAChRs on astrocytes.

\section{a7 $\mathrm{nAChR}$ activation reduces LPS-mediated pro-inflammatory cytokine secretion in astrocytes}

To investigate the effect of $\alpha 7 \mathrm{nAchR}$ activation on the secretion of pro-inflammatory cytokines TNF- $\alpha$ and IL-6, we pretreated astrocytes with $\alpha 7 \mathrm{nAChR}$ agonist GTS21 for $1 \mathrm{~h}$ followed by $24 \mathrm{~h}$ of LPS treatment. To ascertain the dose-response effect of $\alpha 7 \mathrm{nAchR}$ activation on the secretion of TNF- $\alpha$ and IL- 6 , we used increasing doses of GTS21 (from 3 to $100 \mu \mathrm{m}$ ). LPS caused significant increase in IL-6 and TNF- $\alpha$ secretion in these cells and GTS21 pretreatment resulted in a dose-dependent reduction in LPS-mediated IL-6 and TNF- $\alpha$ secretion (Fig. 2a).
No difference in the cell viability was observed due to treatments (data not shown).

To ascertain whether the anti-inflammatory effects observed by GTS21 are specific to $\alpha 7$ nAChRs, GTS21 treatment was done in the presence or absence of the $\alpha 7$ nAChR-specific antagonist, methyllycaconitine (MLA). Following these treatments, cells were activated with LPS and TNF- $\alpha$ and IL- 6 were measured using ELISA in the cellfree supernatant. As demonstrated in Fig. 2b, we observed that treatment with MLA significantly reversed the blockade of TNF- $\alpha$ and IL- 6 secretion by GTS21. We also transduced astrocytes with either lenti short hairpin RNA for $\alpha 7$ nAChR or scrambled shRNA and observed approximately 75\% knockdown using qRT-PCR with TaqMan probes specific for $\alpha 7$ nAchR (Fig. 2c). Upon knockdown of $\alpha 7$

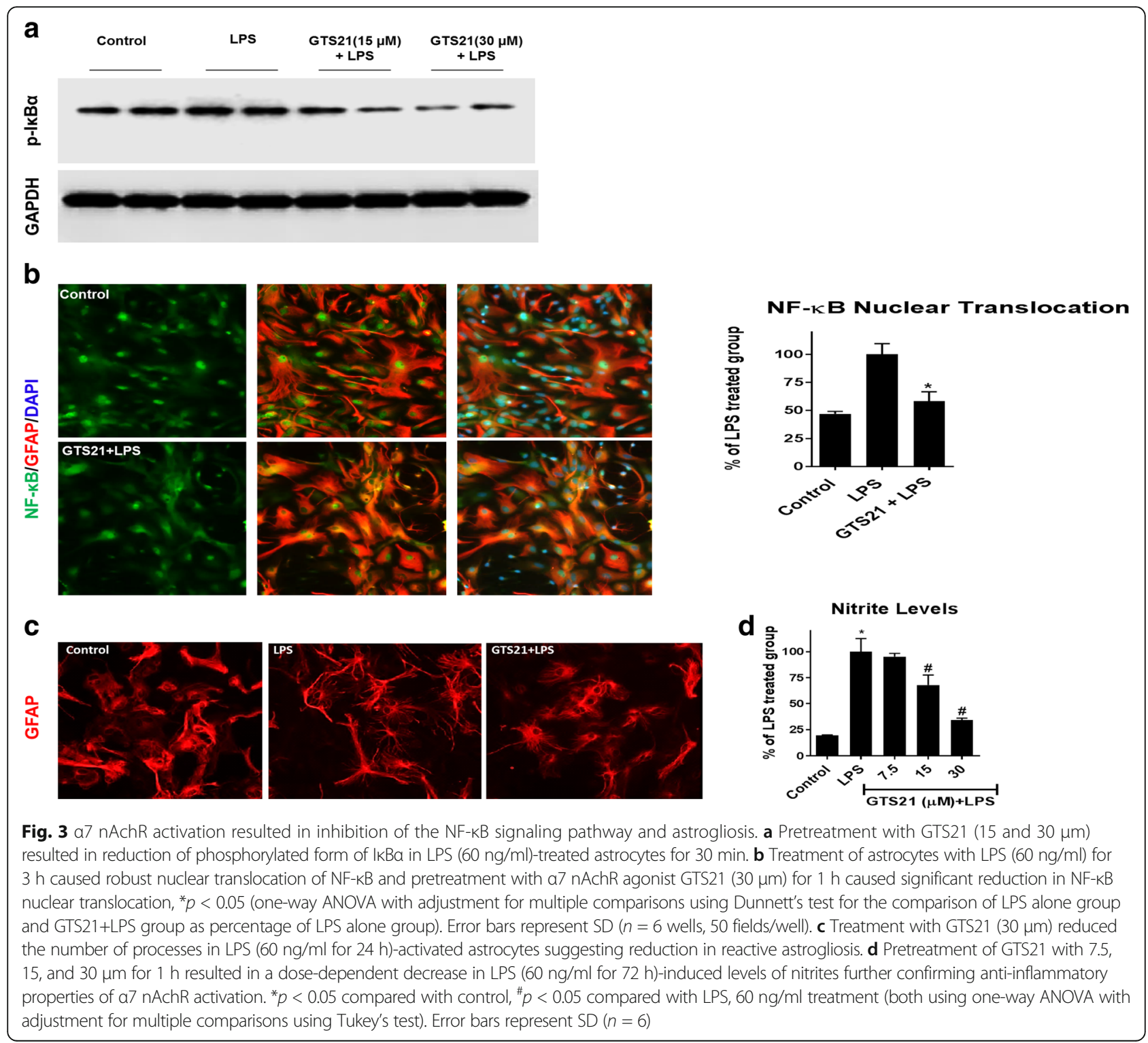


a

LPS treated astrocytes compared to untreated
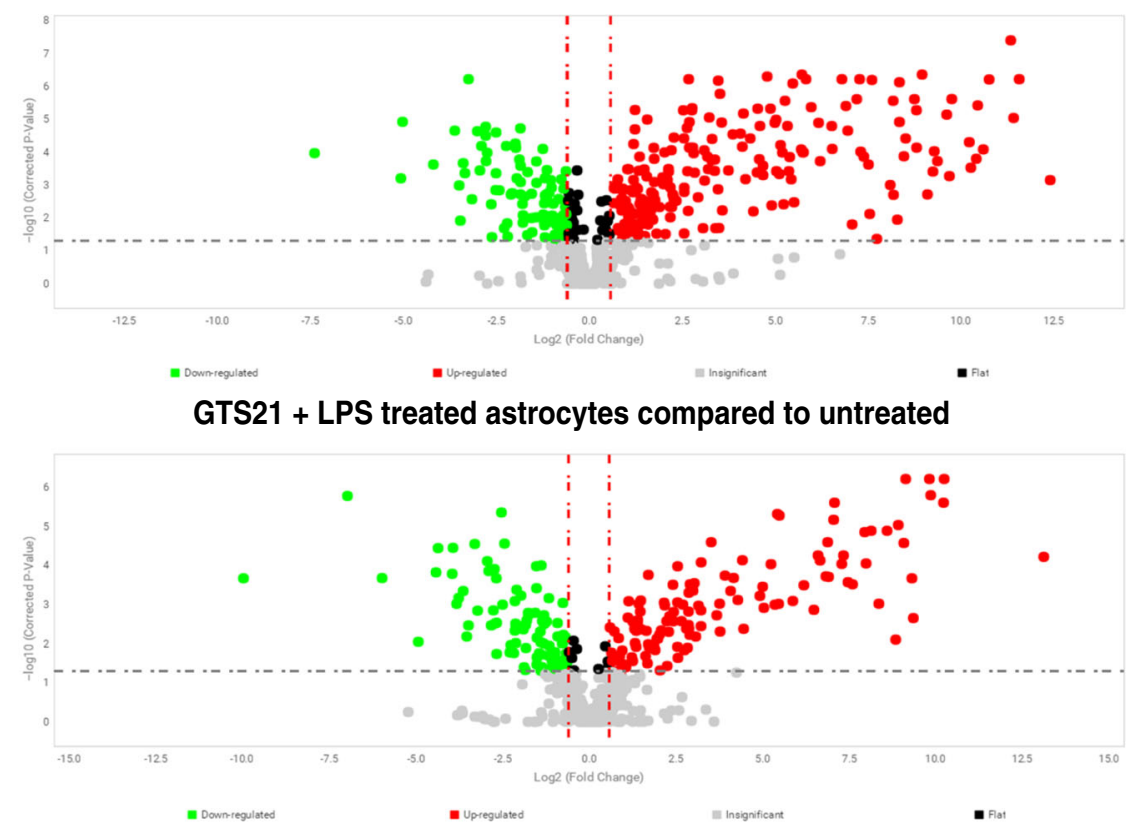

b

NF-KB signaling pathway

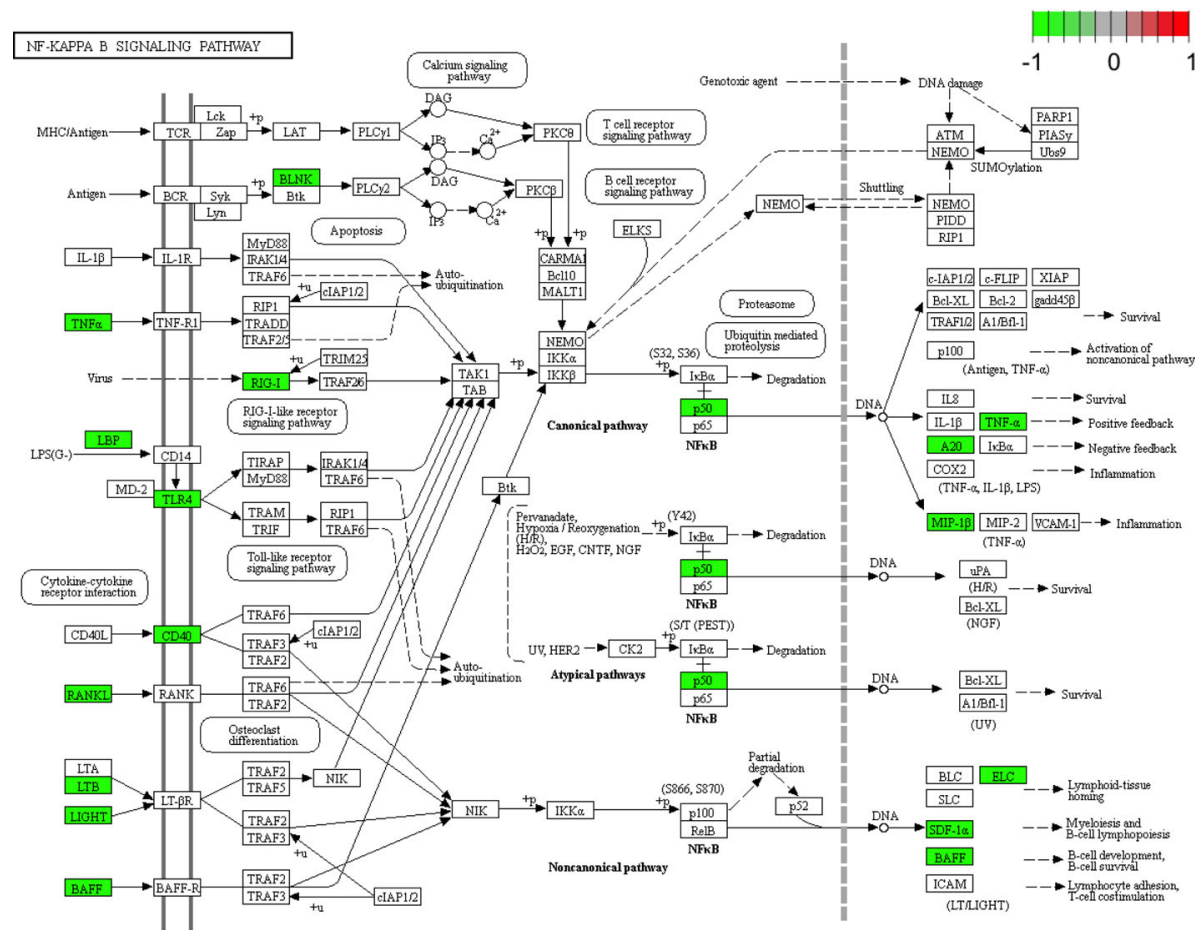

Fig. 4 (See legend on next page.) 


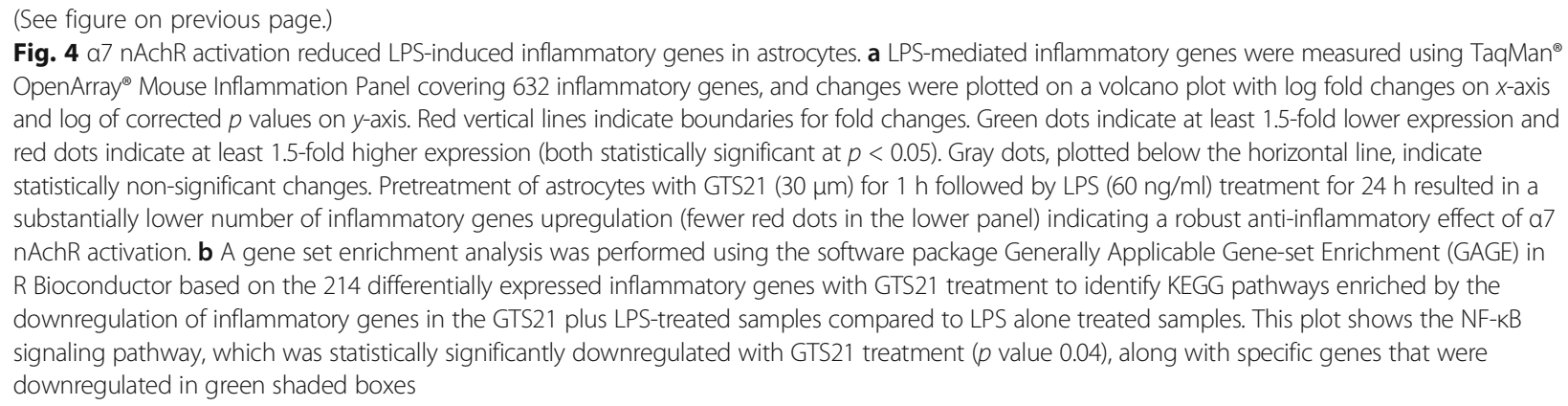

nAChR in astrocytes, GTS21 was unable to reduce the levels of LPS-mediated TNF- $\alpha$ expression (Fig. 2c).

\section{a7 $\mathrm{nAChR}$ activation results in inhibition of the NF-KB signaling pathway}

To investigate the mechanism underlying the antiinflammatory properties of GTS21 in LPS-stimulated astrocytes, we evaluated the effect of GTS21 on the NF-kB pathway. For this experiment, we evaluated different components of this pathway in astrocytes stimulated with LPS in the presence or absence of GTS21 beginning

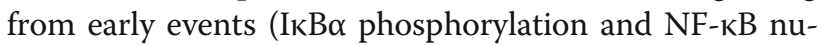
clear translocation) to later events (reactive astrogliosis and nitrite production). First, we evaluated the effect of $\alpha 7$ nAChR activation on $\mathrm{I} \kappa \mathrm{B} \alpha$, which binds to NF- $\mathrm{kB}$ and prevents its nuclear translocation. Phosphorylation of $\mathrm{I} K \mathrm{~B} \alpha$ indicates its inactivation [23, 24]. Astrocytes were pretreated with GTS21, followed by treatment with LPS for 30 min since this event occurs earlier in the NF$\kappa \mathrm{B}$ signaling cascade upon LPS stimulation. Following treatment, the cells were lysed and the phosphorylated form of IKB $\alpha$ was measured. LPS treatment resulted in increased levels of the phosphorylated form of $\mathrm{I} \kappa \mathrm{B} \alpha$, indicating nuclear translocation and activation of the NF-kB pathway. However, pretreatment with GTS21 re-

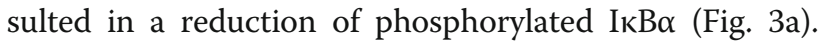
Next, we evaluted nuclear translocation of NF- $\kappa B$ using immunofluorescence with the ArrayScan XTI highcontent analysis system. As shown in Fig. 3b, astrocytes treated with LPS for $3 \mathrm{~h}$ showed robust NF- $\mathrm{kB}$ nuclear translocation, but the $\alpha 7$ nAchR agonist GTS21 significantly decreased this effect. We then evaluated LPS-mediated reactive astrogliosis by monitoring morphological changes in astrocytes upon $\alpha 7$ nAchR activation. Astrocytes were pretreated with GTS21 and stimulated using LPS for $24 \mathrm{~h}$. We observed that treatment with LPS modified the morphology of astrocytes by increasing cell processes and branches. However, GTS21 pretreatment reduced the number of processes in activated astrocytes, suggesting a reduction in reactive astrogliosis (Fig. 3c). Finally, we measured nitrite levels, a breakdown product of the pro-inflammatory signaling molecule nitric oxide, using the Griess reaction. With LPS treatment for $72 \mathrm{~h}$, we observed a significant increase in nitrite levels. However, a dose-dependent decrease in the levels of nitrite was noted with GTS21 pretreatment (Fig. 3d).

\section{a7 $\mathrm{nAChR}$ activation reduces LPS-mediated induction of inflammatory genes associated with the NF-KB signaling pathway}

Mouse astrocytes were treated with PBS alone, PBS in the presence of LPS or GTS21 in the presence of LPS for $24 \mathrm{~h}$. Reverse-transcribed cDNA was loaded to a TaqMan ${ }^{\circ}$ OpenArray ${ }^{\circ}$ mouse inflammation panel covering 632 genes specifically targeted for inflammation. Figure $4 \mathrm{a}$ is a volcano plot demonstrating upregulation of inflammatory genes upon LPS treatment compared to PBS control. Pretreatment with GTS21 resulted in a substantially lower number of inflammatory genes upregulated as compared to LPS indicating a robust anti-inflammatory effect of $\alpha 7 \mathrm{nAChR}$ activation.

We then performed a gene set enrichment analysis using the software package Generally Applicable Geneset Enrichment (GAGE) in R Bioconductor [20] based on the 214 differentially expressed inflammatory genes with GTS21 treatment. In this analysis, we identified the KEGG pathways enriched by the downregulation of inflammatory genes in the GTS21 plus LPS-treated samples compared to LPS alone treated samples. We observed that the NF- $\mathrm{kB}$ signaling pathway was statistically significantly downregulated with GTS21 treatment ( $p$ value 0.04 , Fig. $4 \mathrm{~b}$ ).

\section{a7 $\mathrm{nAChR}$ activation induces upregulation of canonical Nrf2 antioxidant genes}

We measured the expression profiles of a number of canonical Nrf2-responsive antioxidant genes. Pretreatment with GTS21 for $1 \mathrm{~h}$ resulted in a significant upregulation of HO1, TXNRD1, and GCLC in astrocytes treated with LPS for $24 \mathrm{~h}$. This effect was significantly inhibited in the presence of $\alpha 7 \mathrm{nAChR}$ antagonist MLA (Fig. 5a). We also measured protein levels of Nrf2 target genes and found significant increase in HO1, TXNRD1, and NQO1, but no change in GCLC with GTS21 


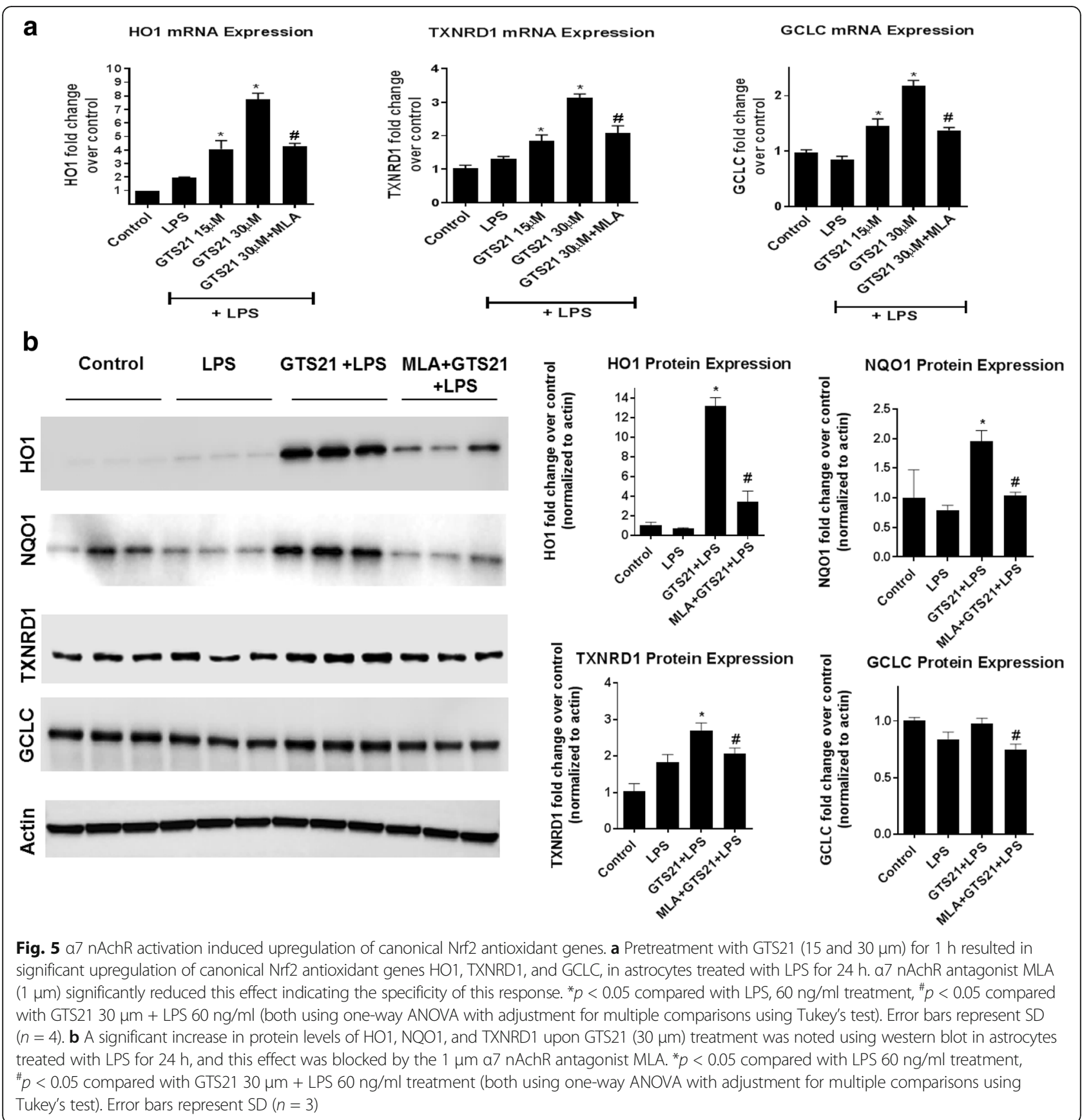

pretreatment in LPS-treated astrocytes (Fig. 5b). Further, a complete loss of this antioxidant response with GTS21 was observed in astrocytes cultured from Nrf2 knockout mice, suggesting that these effects are mediated through Nrf2 signaling (Fig. 6a).

Astrocytes lacking Nrf2 have a reduced anti-inflammatory response to $a 7 \mathrm{nAChR}$ activation

We evaluated the anti-inflammatory effects of GTS21 in astrocytes from Nrf2 knockout mice. Cell-free conditioned medium was collected from astrocytes cultured from either wild-type or Nrf2 knockout mice and treated with LPS for $24 \mathrm{~h}$ in the presence or absence of GTS21. As observed in the earlier experiments, GTS21 significantly reduced LPS-mediated TNF- $\alpha$ production in wild-type astrocytes. However, in Nrf2 knockout astrocytes, this effect was robustly blocked. These results indicate that activation of the Nrf2 pathway may in part be responsible for the antiinflammatory effects of GTS21 (Fig. 6b). 


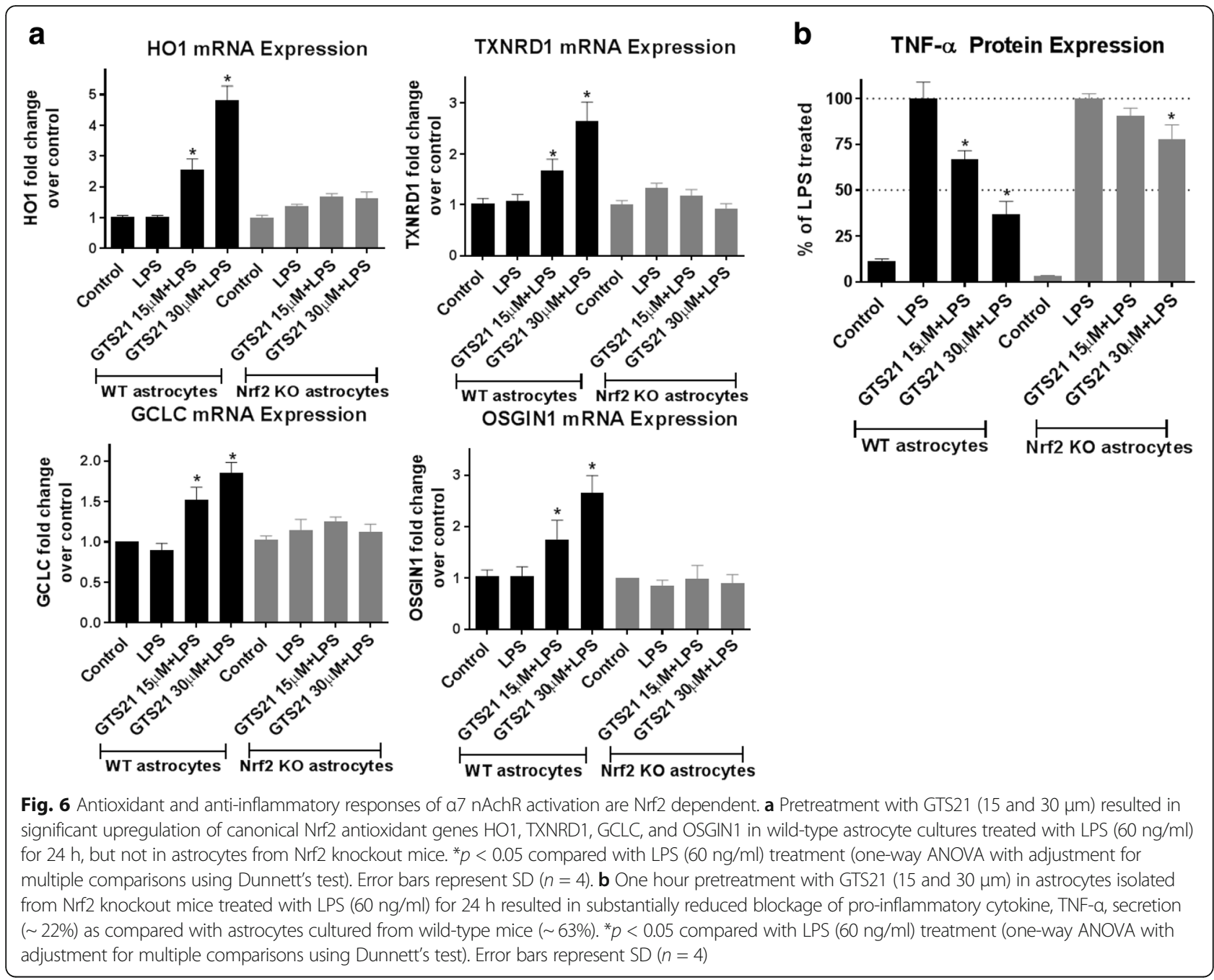

a7 nAChR activation inhibits neuronal apoptosis mediated by inflammatory astrocytes

Purified astrocytes were treated with LPS in the presence or absence of $\alpha 7 \mathrm{nAchR}$ agonist GTS21, and the cellfree conditioned medium was collected for addition to neurons. Significant apoptosis of neurons was observed in the presence of LPS-treated astrocyte conditioned medium. GTS21 pretreated astrocyte conditioned medium resulted in substantially reduced caspase activation suggesting less apoptosis. This effect was reversed by the $\alpha 7 \mathrm{nAchR}$ antagonist MLA, indicating the specificity of the response (Fig. 7a, b).

a7 $\mathrm{nAChR}$ activation reduces NF-KB luciferase signal and pro-inflammatory genes downstream of the NF-KB signaling pathway in brain

To study the effect of $\alpha 7 \mathrm{nAChR}$ activation on LPSinduced NF- $\kappa B$ luciferase signal in vivo, we used transgenic reporter mice where luciferase expression is driven by NF- $\mathrm{B}$ activation. In the presence of luciferin, this expression results in bioluminescence, which was imaged and quantified. NF- $\mathrm{kB}$ activation was induced with LPS treatment. At $4 \mathrm{~h}$ of LPS treatment, there was a significant increase in NF- $\kappa B$ luciferase signal in the brain as compared to the PBS-treated control group. Animals injected with $25 \mathrm{mg} / \mathrm{kg}$ GTS21 demonstrated a reduction in the LPS-mediated NF- $\mathrm{kB}$ luciferase signal in the brains compared to LPS only treated animals (Fig. 8a, b).

After imaging, the other hemisphere of the brain was collected for RNA analysis of inflammatory cytokine downstream of the NF- $\mathrm{BB}$ signaling pathway. In mice treated with GTS21, significant reductions in gene expression of inflammatory cytokines TNF- $\alpha$, IL-1 $\beta$, and IL-6 were observed in the brain as compared to LPS only treated animals (Fig. 8c). We also measured the expression of the genes involved in the Nrf2 signaling pathway and observed increased expression of two Nrf2 target genes with GTS21 treatment in the brain as compared to the PBS-treated group: HO1 and oxidative stress-induced growth inhibitor (OSGIN1), which is 


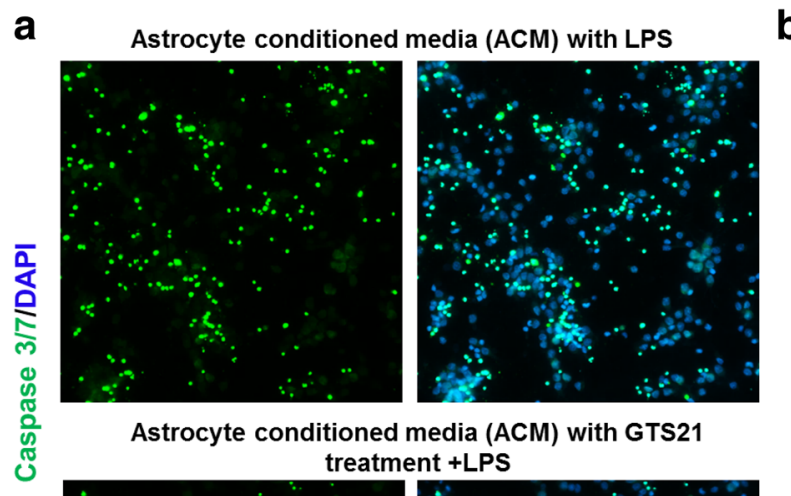

b Caspase $3 / 7$ Activation in Neurons
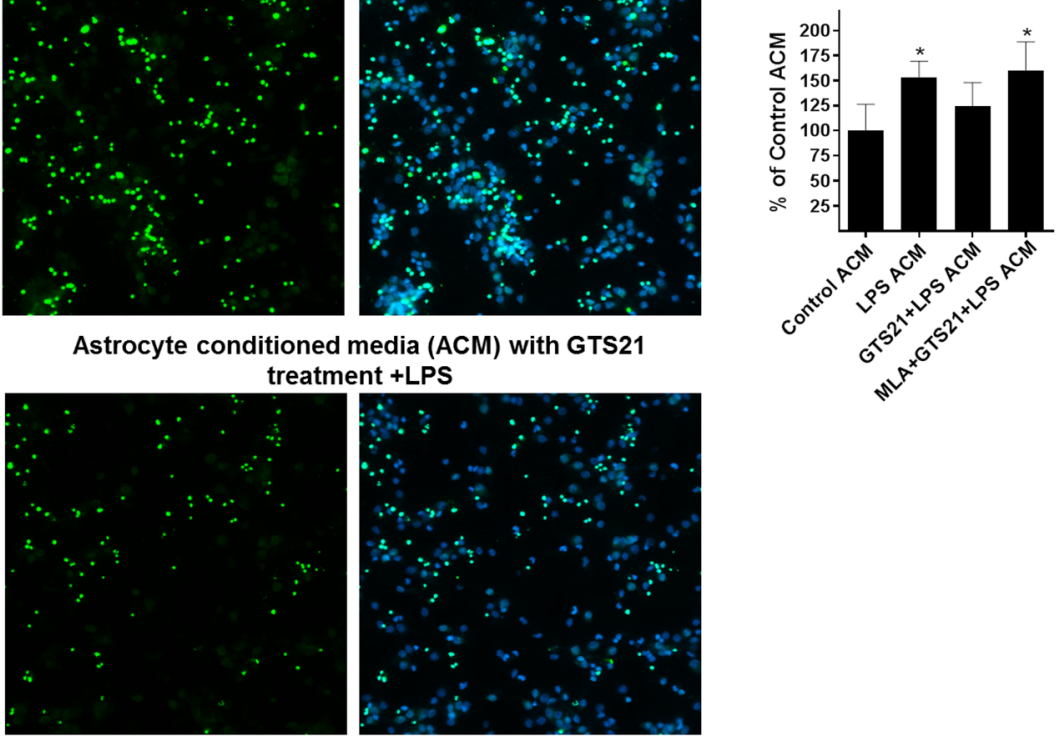

Fig. 7 a7 nAchR activation reduced inflammatory astrocyte-mediated neuronal apoptosis. a Representative images of caspase activation in neurons treated with astrocyte conditioned media in the presence of LPS (60 $\mathrm{ng} / \mathrm{ml}$ ) for $24 \mathrm{~h}$ with or without $1 \mathrm{~h}$ GTS21 pretreatment (30 $\mu \mathrm{m})$. b Quantification of caspase activation upon GTS21 $(30 \mu \mathrm{m})$ pretreatment for $1 \mathrm{~h}$ in LPS (60 ng/ml)-activated astrocyte conditioned media showed significantly lowered levels of caspase 3/7 in neuronal cultures, and this effect was significantly blocked upon addition of $1 \mu \mathrm{m}$ MLA, ${ }^{*} p<0.05$ compared with control astrocyte conditioned media. ${ }^{*} p<0.05$ compared with control (one-way ANOVA with adjustment for multiple comparisons using Dunnett's test). Error bars represent SD ( $n=5$ wells, 15 fields per well)

activated early in the process of Nrf2 activation in the brain [25]. However, there was no significant difference in HO1 and OSGIN1 expression between LPS-treated group and LPS+GTS21-treated group (Fig. 8d). Collectively, these results demonstrate that activation of $\alpha 7$ nAChRs results in inhibition of the NF-kB pathway and upregulation of antioxidant Nrf2 target genes in an animal model of neuroinflammation.

\section{Discussion}

In this study, treatment of astrocytes with $\alpha 7 \mathrm{nAChR}$ agonist GTS21 [26] reduced LPS-mediated inflammatory cytokines in a dose-dependent manner and this effect was reversed by both pharmacological and genetic inhibition of $\alpha 7 \mathrm{nAChR}$ expression. Further, $\alpha 7 \mathrm{nAChR}$ activation blocked LPS-mediated NF- $\mathrm{B}$ n nuclear translocation in astrocytes indicating that the observed anti-inflammatory effect may be mediated through the NF-kB pathway. We also demonstrated that treatment with $\alpha 7 \mathrm{nAChR}$ agonist upregulated canonical Nrf2 antioxidant genes and proteins suggesting antioxidant properties of $\alpha 7 \mathrm{nAch}$. Using an astrocyte conditioned media approach, we demonstrated a reduction in neuronal apoptosis with GTS21 treatment. Finally, in an in vivo neuroinflammation model using LPS in NF- $\mathrm{kB}$ luciferase reporter mice, we demonstrated reduction in LPS-induced NF- $\mathrm{kB}$ activity in the brains of animals treated with GTS21 using bioluminescent imaging. We also observed a reduction in the expression of pro-inflammatory cytokine downstream of the NF-kB pathway and an increase in Nrf2 target genes in brain tissues with GTS21 treatment.

$\alpha 7 \mathrm{nAChRs}$ have been recognized as a target with therapeutic relevance in neurodegenerative diseases because of their neuroprotective effects and potential association with cognitive enhancement $[27,28]$. A distinct feature of these receptors is that they are widely expressed in neuronal and non-neuronal cells, including astrocytes, which are emerging as important players in neuroinflammation and cognitive impairment $[17,18]$. However, the specific role of astroglial $\alpha 7 \mathrm{nAChRs}$ in neuroprotection has only been evaluated in a couple of prior investigations from a single laboratory. In one study, Liu et al. demonstrated that activation of astroglial $\alpha 7 \mathrm{nAChRs}$ may provide protection against degeneration of dopaminergic neurons by inhibition of MPTP (in vivo) - and MPP+- or LPS (in vitro)-induced astrocyte activation in PD [12]. In a second study, Liu et al. demonstrated that activation of $\alpha 7$ nAChRs resulted in a reduction in $\mathrm{H}_{2} \mathrm{O}_{2}$-induced apoptosis of astrocytes and expression of glial cell-derived neurotrophic factor [29]. Both of these studies point towards a critical role of astrocytes in neuroprotection conferred by $\alpha 7$ nAChR activation. The results from our study provide additional evidence for anti-inflammatory and antioxidant effects of astroglial $\alpha 7 \mathrm{nAChR}$ activation. 


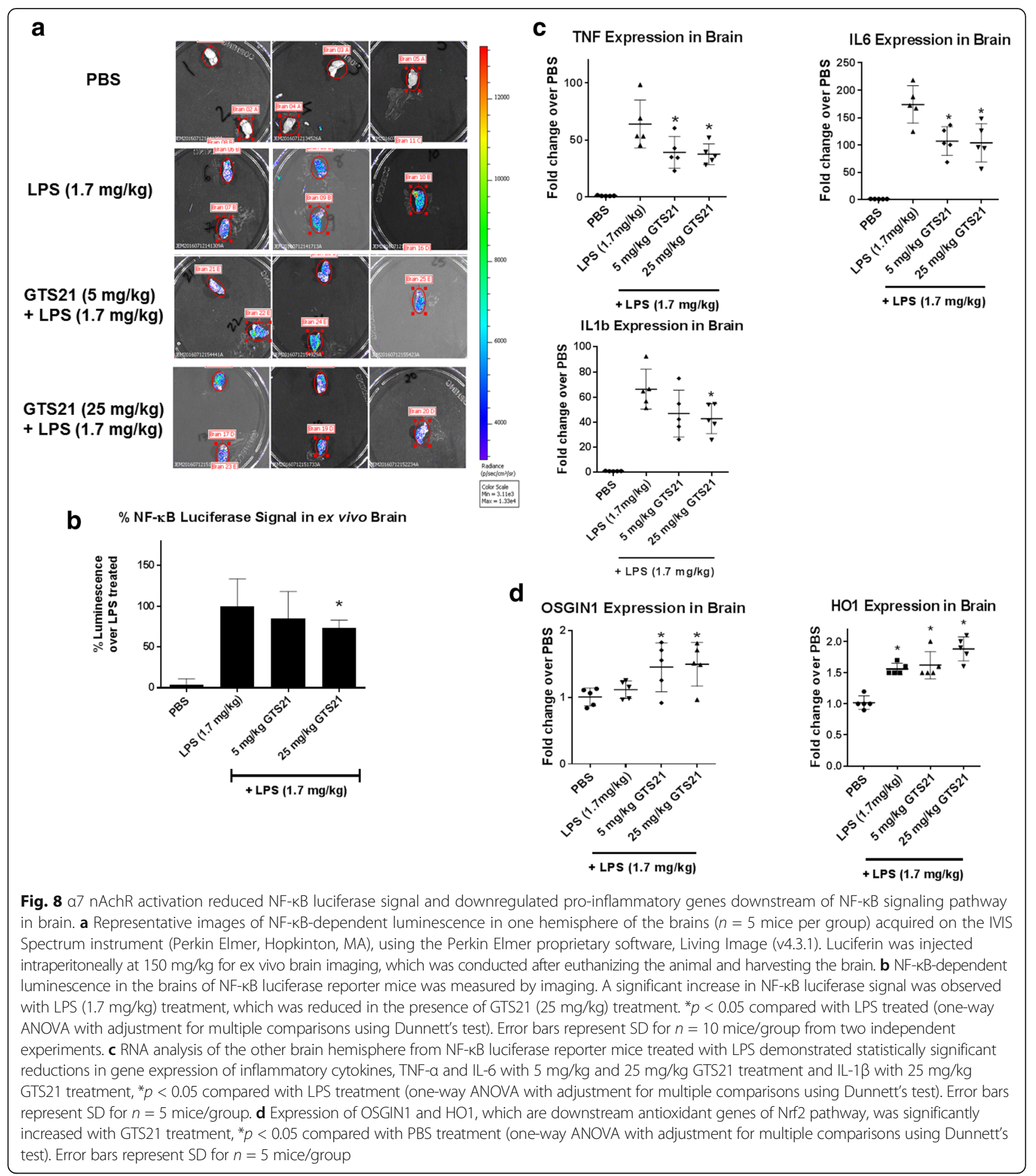

Further, our study also provides an explanation of the molecular mechanism of action for the observed antiinflammatory effects of astroglial $\alpha 7 \mathrm{nAChR}$ activation. In LPS-treated astrocyte cultures from Nrf2 knockout mice, we not only observed a robust reduction of the antioxidant response of $\alpha 7$ nAchR activation but also the antiinflammatory response in the in vitro inflammation model; suggesting that the Nrf2 and NF- $\kappa B$ pathways may work in concert to mediate the observed anti-inflammatory response of astroglial $\alpha 7$ nAchRs. Previous investigations have proposed multiple mechanisms by which the Nrf2 and NF- $\mathrm{kB}$ pathways may interact. First, the activation of the Nrf2 pathway leads to dissociation of Nrf2-Keap1 complex and increased free Kelch-like ECH-associated protein 
1 (Keap1) in the cytosol. Keap1 is reported to bind with IKK $\beta$, which may in turn prevent the phosphorylation of ІкB $\alpha$ and $\mathrm{p} 65$ NF- $\mathrm{\kappa B}$ subunit nuclear translocation leading to diminished NF- $\mathrm{kB}$ signaling [30]. On the other hand, Keap1 is also reported to be capable of binding directly with the p65 subunit of NF- $\mathrm{kB}$ [31]. Therefore, upon activation of the NF- $\mathrm{kB}$ pathway, this interaction may result in higher nuclear translocation of Keap1 and consequent functional inactivation of Nrf2, in turn exaggerating the inflammatory response. Another potential interaction between the two pathways involves CREB-binding protein (CBP), which is a transcription co-activator capable of binding to both Nrf2 and the phosphorylated p65 subunit of NF-kB [32]. Since Nrf2 and NF- $k B$ compete for CBP, knocking out Nrf2 results in higher binding of NF-kB/p65 to $\mathrm{CBP}$ and consequently higher transcription of inflammatory genes, leading to a more potent inflammatory response. Our observation of decreased anti-inflammatory response of $\alpha 7 \mathrm{nAChR}$ activation in astrocytes from $\mathrm{Nrf} 2$ knockout mice is consistent with this hypothesis.

The Nrf2 pathway has received increasing recognition as a major player in glial $\alpha 7 \mathrm{nAChRs-mediated} \mathrm{neuro-}$ protection. Parada et al. reported that cell death and ROS production were reduced upon treatment with $\alpha 7$ nAChR agonist PNU282987 in organotypic hippocampal slice cultures under oxygen and glucose deprivation conditions, and these effects were reduced substantially upon immunotoxic depletion of microglial cells [33]. In vivo, these significantly diminished antioxidant and neuroprotective effects were noted upon $\alpha 7 \mathrm{nAChR}$ activation in $\mathrm{HO} 1$ knockout mice, suggesting active involvement of the Nrf2 pathway in neuroprotection against brain ischemia. Findings from our study confirm these observations regarding the importance of the Nrf2 pathway in glial $\alpha 7 \mathrm{nAChR}$-mediated neuroprotection. Aditionally, our study critically notes that the Nrf2 pathway is not only involved in $\alpha 7 \mathrm{nAChR}$-mediated antioxidant effects, but may also interact with the NF- $\mathrm{kB}$ pathway to reduce pro-inflammatory cytokine secretion.

Activation of functional $\alpha 7 \mathrm{nAChRs}$ expressed on astrocytes has been demonstrated to produce rapid currents and increase intracellular calcium levels [11]. After an initial influx of calcium through astroglial $\alpha 7 \mathrm{nAChR}$ channels, further modulation of calcium signaling occurs through calcium-induced calcium release from intracellular store [34]. Increase in intracellular calcium in astrocytes is reported to regulate synaptic transmission and plasticity $[35,36]$. Astrocytes reside in close proximity to neurons and are key components of neural circuits. Recent evidence suggests that calcium signaling cascades in astrocytes result in increased extracellular glutamate levels, thereby shifting the local neural circuit to a slow oscilation state of synchronized neuronal firing critical in memory consolidation and sleep [37]. Taken together, these studies suggest that activation of astroglial $\alpha 7 \mathrm{nAChRs}$ may play a role in enhancement of cognitive function. Our results showing anti-inflammatory and antioxidant properties of astroglical $\alpha 7 \mathrm{nAChRs}$ suggest that in pathological states such as neurodegenerative diseases, targeting these receptors can provide additional benefits through neuroprotection.

\section{Conclusion}

In conclusion, our results suggest that activating astroglial $\alpha 7$ nAChRs may have a role in neuroprotection by decreasing inflammation and oxidative stress, and therefore could have therapeutic implications for the development of disease modifying treatments for neurodegenerative diseases. The anti-inflammatory effects observed with activation of astroglial $\alpha 7 \mathrm{nAChRs}$ appear to be mediated through an interaction of the Nrf2 and NF-kB pathways. Our findings of robust anti-inflammatory and antioxidant effects of astroglial $\alpha 7 \mathrm{nAChR}$ stimulation provide a compelling rationale for future research evaluating this response in specific neurodegenerative disease models to guide development of novel therapeutics targeting these receptors.

\section{Abbreviations}

CBP: CREB-binding protein; CNS: Central nervous system; GAPDH: Glyceraldehyde3-phosphate dehydrogenase; GCLC: Glutamate-cysteine ligase catalytic subunit; GFAP: Glial fibrillary acidic protein; HO1: Heme oxygenase 1; I kB: Nuclear factor of kappa light polypeptide gene enhancer in B cell inhibitor, alpha; IL: Interleukin; Keap1: Kelch-like ECH-associated protein 1; LPS: Lipopolysaccharide; MPP+: 1-Methyl-4-phenylpyridinium ion; MPTP: 1-Methyl-4-phenyl-1,2,3,6tetrahydropyridine; nAChRs: a7 nicotinic acetylcholine receptors; NF-kB: Nuclear factor kappa-light-chain-enhancer of activated B cells; $\mathrm{NO}$ : Nitric oxide; $\mathrm{NO}_{2}^{-}$: Nitrite; NQO1: NAD(P)H:quinone oxidoreductase-1; Nrf2: Nuclear factor erythroid-derived 2-related factor 2; OSGIN1: Oxidative stress-induced growth inhibitor 1;

ROS: Reactive oxygen species; TNF-a: Tumor necrosis factor alpha;

TXNRD1: Thioredoxin reductase 1

\section{Acknowledgements}

We thank John Gatley, Greg Miller, and Heather Brenhouse from Northeastern University for their mentorship and valuable feedback during the course of this research.

\section{Funding}

Biogen provided funding for this study as a part of Dr. Patel's doctoral training. Authors designed this study independently, and funders played no additional role in design of this study or writing of the manuscript.

Availability of data and materials

Please contact the corresponding author for data requests.

\section{Authors' contributions}

$H P, A D$, and $R L$ conceptualized the study and designed the experiments. HP conducted all the experiments, analyzed the data, and wrote the manuscript. JM and SR contributed to in vivo imaging studies. All authors read and approved the final version of this manuscript.

\section{Ethics approval and consent to participate}

All procedures involving animals were approved by the Biogen Institutional Animal Care and Use Committee (IACUC), which is accredited by the Association for Assessment and Accreditation of Laboratory Animal Care International. 


\section{Competing interests}

This research was conducted as a partial fulfillment of Dr. Patel's doctoral program requirement at Northeastern University in Boston, MA, in collaboration with Biogen. Dr. Dunah, Ms. Ryan, and Ms. McIntyre are employees of Biogen. Dr. Patel is currently a full-time employee of Abbvie. The authors declare that they have no competing interests.

\section{Publisher's Note}

Springer Nature remains neutral with regard to jurisdictional claims in published maps and institutional affiliations.

\section{Author details}

'Department of Pharmaceutical Sciences, Northeastern University, Boston, MA, USA. ${ }^{2}$ Neurology Research, Biogen, 225 Binney street, Cambridge, MA 02142, USA. ${ }^{3}$ Pre-Clinical Imaging \& Pharmacology, Biogen, Cambridge, MA, USA.

Received: 15 May 2017 Accepted: 18 September 2017

Published online: 26 September 2017

\section{References}

1. Quik M, Zhang D, McGregor M, Bordia T. Alpha7 nicotinic receptors as therapeutic targets for Parkinson's disease. Biochem Pharmacol. 2015;97(4): 399-407.

2. Bencherif M, Narla ST, Stachowiak MS. Alpha7 neuronal nicotinic receptor: a pluripotent target for diseases of the central nervous system. CNS Neurol Disord Drug Targets. 2014;13:836-45.

3. Kihara T, Sawada H, Nakamizo T, Kanki R, Yamashita H, Maelicke A, Shimohama S. Galantamine modulates nicotinic receptor and blocks A $\beta$-enhanced glutamate toxicity. Biochem Biophys Res Commun. 2004;325:976-82.

4. Del Barrio L, Martin-de-Saavedra MD, Romero A, Parada E, Egea J, Avila J, McIntosh JM, Wonnacott S, Lopez MG. Neurotoxicity induced by okadaic acid in the human neuroblastoma SH-SY5Y line can be differentially prevented by a7 and $\beta 2^{*}$ nicotinic stimulation. Toxicol Sci. 2011;123:193-205.

5. Parada E, Egea J, Romero A, del Barrio L, Garcia AG, Lopez MG. Poststress treatment with PNU282987 can rescue SH-SY5Y cells undergoing apoptosis via alpha7 nicotinic receptors linked to a Jak2/Akt/HO-1 signaling pathway. Free Radic Biol Med. 2010;49:1815-21.

6. Li Y, King MA, Meyer EM. a7 nicotinic receptor-mediated protection against ethanol-induced oxidative stress and cytotoxicity in PC12 cells. Brain Res. 2000;861:165-7.

7. Takada Y, Yonezawa A, Kume T, Katsuki H, Kaneko S, Sugimoto H, Akaike A. Nicotinic acetylcholine receptor-mediated neuroprotection by donepezi against glutamate neurotoxicity in rat cortical neurons. J Pharmacol Exp Ther. 2003;306:772-7.

8. Nakamizo T, Kawamata J, Yamashita H, Kanki R, Kihara T, Sawada H, Akaike A, Shimohama S. Stimulation of nicotinic acetylcholine receptors protects motor neurons. Biochem Biophys Res Commun. 2005:330:1285-9.

9. Jonnala RR, Terry AV Jr, Buccafusco JJ. Nicotine increases the expression of high affinity nerve growth factor receptors in both in vitro and in vivo. Life Sci. 2002;70:1543-54

10. Egea J, Rosa AO, Sobrado M, Gandia L, Lopez MG, Garcia AG. Neuroprotection afforded by nicotine against oxygen and glucose deprivation in hippocampal slices is lost in a7 nicotinic receptor knockout mice. Neuroscience. 2007;145:866-72

11. Shen J-x, Yakel JL. Functional a7 nicotinic ACh receptors on astrocytes in rat hippocampal CA1 slices. J Mol Neurosci. 2012;48:14-21.

12. Liu Y, Hu J, Wu J, Zhu C, Hui Y, Han Y, Huang Z, Ellsworth K, Fan W. a7 nicotinic acetylcholine receptor-mediated neuroprotection against dopaminergic neuron loss in an MPTP mouse model via inhibition of astrocyte activation. J Neuroinflammation. 2012;9:98.

13. Sugano N, Shimada K, Ito K, Murai S. Nicotine inhibits the production of inflammatory mediators in U937 cells through modulation of nuclear factor-kB activation. Biochem Biophys Res Commun. 1998;252:25-8.

14. Wang $H$, Liao H, Ochani M, Justiniani M, Lin X, Yang L, Al-Abed Y, Wang $H$, Metz C, Miller EJ, et al. Cholinergic agonists inhibit HMGB1 release and improve survival in experimental sepsis. Nat Med. 2004;10:1216-21.

15. Han Z, Li L, Wang L, Degos V, Maze M, Su H. Alpha-7 nicotinic acetylcholine receptor agonist treatment reduces neuroinflammation, oxidative stress, and brain injury in mice with ischemic stroke and bone fracture. J Neurochem. 2014;131:498-508.
16. Navarro E, Buendia I, Parada E, Leon R, Jansen-Duerr P, Pircher H, Egea J, Lopez MG. Alpha7 nicotinic receptor activation protects against oxidative stress via heme-oxygenase I induction. Biochem Pharmacol. 2015;97(4):473-481.

17. Osso LA, Chan JR. Astrocytes underlie neuroinflammatory memory impairment. Cell. 2015;163:1574-6.

18. Habbas S, Santello M, Becker D, Stubbe H, Zappia G, Liaudet N, Klaus FR, Kollias G, Fontana A, Pryce CR. Neuroinflammatory TNFa impairs memory via astrocyte signaling. Cell. 2015;163:1730-41.

19. McCarthy KD, de Vellis J. Preparation of separate astroglial and oligodendroglial cell cultures from rat cerebral tissue. J Cell Biol. 1980;85:890-902.

20. Luo W, Friedman MS, Shedden K, Hankenson KD, Woolf PJ. GAGE: generally applicable gene set enrichment for pathway analysis. BMC Bioinformatics. 2009;10:161.

21. Carlsen H, Moskaug J $\varnothing$, Fromm SH, Blomhoff R. In vivo imaging of NF-KB activity. J Immunol. 2002;168:1441-6.

22. Gorina R, Font-Nieves M, Márquez-Kisinousky L, Santalucia T, Planas AM. Astrocyte TLR4 activation induces a proinflammatory environment through the interplay between MyD88-dependent NFKB signaling, MAPK, and Jak1/ Stat1 pathways. Glia. 2011;59:242-55.

23. Chen ZJ, Parent L, Maniatis T. Site-specific phosphorylation of IkBa by a novel ubiquitination-dependent protein kinase activity. Cell. 1996;84:853-62.

24. Alkalay I, Yaron A, Hatzubai A, Orian A, Ciechanover A, Ben-Neriah Y Stimulation-dependent I kappa B alpha phosphorylation marks the NF-kappa B inhibitor for degradation via the ubiquitin-proteasome pathway. Proc Natl Acad Sci. 1995;92:10599-603.

25. Brennan MS, Patel H, Allaire N, Thai A, Cullen P, Ryan S, Lukashev M, Bista P, Huang R, Rhodes KJ. Pharmacodynamics of dimethyl fumarate are tissue specific and involve NRF2-dependent and-independent mechanisms. Antioxid Redox Signal. 2016;24:1058-71.

26. Kem WR, Mahnir VM, Prokai L, Papke RL, Cao X, LeFrancois S, Wildeboer K, Prokai-Tatrai K, Porter-Papke J, Soti F. Hydroxy metabolites of the Alzheimer's drug candidate 3-[(2, 4-dimethoxy) benzylidene]-anabaseine dihydrochloride (GTS-21): their molecular properties, interactions with brain nicotinic receptors, and brain penetration. Mol Pharmacol. 2004;65:56-67.

27. Medeiros R, Castello NA, Cheng D, Kitazawa M, Baglietto-Vargas D, Green KN, Esbenshade TA, Bitner RS, Decker MW, LaFerla FM. a7 Nicotinic receptor agonist enhances cognition in aged 3xTg-AD mice with robust plaques and tangles. Am J Pathol. 2014;184:520-9.

28. Mazurov AA, Kombo DC, Hauser TA, Miao L, Dull G, Genus JF, Fedorov NB, Benson L, Sidach S, Xiao Y, et al. Discovery of (2S,3R)-N-[2-(pyridin-3-ylmethyl)1-azabicyclo[2.2.2]oct-3-yl]benzo[b]furan-2-car boxamide (TC-5619), a selective alpha7 nicotinic acetylcholine receptor agonist, for the treatment of cognitive disorders. J Med Chem. 2012;55:9793-809.

29. Liu Y, Zeng X, Hui Y, Zhu C, Wu J, Taylor DH, Ji J, Fan W, Huang Z, Hu J. Activation of alpha7 nicotinic acetylcholine receptors protects astrocytes against oxidative stress-induced apoptosis: implications for Parkinson's disease. Neuropharmacology. 2015;91:87-96.

30. Kim JE, You DJ, Lee C, Ahn C, Seong JY, Hwang Jl. Suppression of NF-kappaB signaling by KEAP1 regulation of IKKbeta activity through autophagic degradation and inhibition of phosphorylation. Cell Signal. 2010;22:1645-54.

31. Yu M, Li H, Liu Q, Liu F, Tang L, Li C, Yuan Y, Zhan Y, Xu W, Li W, et al. Nuclear factor p65 interacts with Keap1 to repress the Nrf2-ARE pathway. Cell Signal. 2011;23:883-92.

32. Liu GH, Qu J, Shen X. NF-kappaB/p65 antagonizes Nrf2-ARE pathway by depriving CBP from Nrf2 and facilitating recruitment of HDAC3 to MafK. Biochim Biophys Acta. 2008;1783:713-27.

33. Parada E, Egea J, Buendia I, Negredo P, Cunha AC, Cardoso S, Soares MP, Lopez MG. The microglial a7-acetylcholine nicotinic receptor is a key element in promoting neuroprotection by inducing heme oxygenase-1 via nuclear factor erythroid-2-related factor 2. Antioxid Redox Signal. 2013;19:1135-48.

34. Sharma G, Vijayaraghavan S. Nicotinic cholinergic signaling in hippocampal astrocytes involves calcium-induced calcium release from intracellular stores. Proc Natl Acad Sci. 2001;98:4148-53.

35. Perea G, Araque A. Properties of synaptically evoked astrocyte calcium signal reveal synaptic information processing by astrocytes. J Neurosci. 2005;25:2192-203.

36. Agulhon C, Petravicz J, McMullen AB, Sweger EJ, Minton SK, Taves SR, Casper KB, Fiacco TA, McCarthy KD. What is the role of astrocyte calcium in neurophysiology? Neuron. 2008;59:932-46.

37. Poskanzer KE, Yuste R. Astrocytes regulate cortical state switching in vivo. Proc Natl Acad Sci. 2016;113:E2675-84. 